\title{
How psychological dispositions influence the theology of the afterlife
}

\author{
Helen De Cruz and Johan De Smedt \\ Forthcoming in B. Matheson \& Y. Nagasawa (Eds.), Palgrave handbook of the \\ afterlife. Basingstoke: Palgrave Macmillan.
}

\begin{abstract}
Humans across cultures have formulated rich views about what happens after death, including reincarnationist beliefs and beliefs in an afterlife. Theologians further develop and elaborate these views. Recent work in the cognitive science of religion suggests that afterlife beliefs are caused by psychological dispositions that are a stable part of human cognition. For instance, humans intuitively conceptualize themselves and others as composed of material and nonmaterial parts, which facilitates the idea that physical death is not the end of personhood. In this paper, we explore how psychological dispositions influence theological views of the afterlife, focusing on Mormon theology.
\end{abstract}

\section{Introduction}

Most religions affirm an explicit belief in an afterlife, i.e., that biological death is not the end of a human being's existence. Recent research in the cognitive science of religion indicates that cross-culturally widespread beliefs in a life after death are cognitively natural: they arise spontaneously, without explicit instruction, and even in the absence of any cultural input. Humans think of the human person as consisting of one or more material and immaterial entities (e.g., a body and a soul, or a body, mind, and soul). The aim of this paper is to examine how theological views on the afterlife are influenced by evolved cognitive dispositions. We start out by reviewing theories in the cognitive science of religion on afterlife beliefs, looking at different psychological dispositions that contribute to such beliefs, with a focus on intuitive concepts of personhood. We then examine Mormon theological views of the afterlife, and trace their origins to evolved features of human psychology.

\section{Cognitive theories on afterlife beliefs}

Human cultures exhibit a wide variety of beliefs about what happens to people after they die. Some religions, such as traditional Shinto, classical paganism, and Judaism, do not provide an elaborate belief in an afterlife, but conceptualize a vague and indeterminate place (Yomi, Hades, Sheol) where people continue to exist after death as a shadow of their former selves. Other religions, such as the traditional beliefs of the Trobriand Islands and Hinduism, propose that humans and other creatures reincarnate into new bodies in a cyclical pattern of death and rebirth, perhaps ending by being absorbed into a universal consciousness. Yet other religions, such as Islam and Christianity, picture a rich and elaborate afterlife, in a pleasant park-like environment (Heaven) or in a horrible place of torment (Hell).

In spite of this diversity, there are cross-cultural similarities. Humans are not, by default, materialist monists. They believe that some non-physical part(s) of the human person continue to exist after death. This is remarkable, since even preschoolers realize that the biological death of an organism, such as a pet, is irreversible, and that it permanently ends its biological functions (Barrett \& Behne 2005). Even in contemporary western culture, with its monist scientific picture of human personhood, the majority of people continue to believe in some postmortem 
existence. How can we explain the ubiquity of afterlife beliefs, given that there is no clear empirical evidence for life after death? We propose that afterlife beliefs have multiple causal factors, and will here consider some of them ${ }^{1}$. These dispositions explain why such beliefs are widespread, and can account for some of the different forms they can take.

\subsection{Humans are not intuitive physicalists (although it is unclear what they are)}

A wealth of research indicates that humans do not equate personhood with the physical body. In a series of experiments, Bering and Bjorklund (2004) demonstrated that young children draw an intuitive distinction between the biological functions of an organism (which cease at death) and its psychological properties (which they believe continue after death). Children aged between four and eight saw a puppet show where an alligator ate a mouse. After witnessing this event, the experimenter said "Well, it looks like Brown Mouse got eaten by Mr. Alligator. Brown Mouse is not alive anymore" (Bering \& Bjorklund, 2004, 220). When prompted, the vast majority of participants agreed the mouse was dead. They were then asked whether it could still perform biological functions (e.g., eat, run) and whether it still had psychological functions (e.g., knowing it's not alive, wanting to go home). While preschoolers realized that the biological functions had ceased, they believed that psychological functions continued, for instance, that the mouse would still love its mommy. This tendency decreased somewhat in the older children, suggesting that this belief was not a result of cultural learning, where we expect see the opposite pattern.

More recently, Emmons and Kelemen (2014) found that children from Ecuador aged five to twelve, drawn from the rural indigenous Shuar and a more urban population, hold an intuitive belief in pre-existence, i.e., they believe they existed before their mothers were pregnant with them. Participants were asked if they could feel, know, and think things before their mothers were pregnant with them. Whereas older children realized they were not bodily present prior to their biological conception, they still attributed desires and emotions to their pre-conception selves. Since prelife beliefs are not part of the belief systems of rural and urban Ecuador populations (who are predominantly Roman Catholic), this finding supports the view that belief in personal continuity before and after one's physical lifespan is not a result of cultural learning. Similarly, Giménez-Dasí et al. (2005) found that young children believe their friend and God existed in the time of the dinosaurs and would never die, but by the time they are age five, they realize only God is eternal, whereas their friend was not around in the time of the dinosaurs and would die at some point.

Bloom $(2004,2007)$ has argued that belief in the continuity of mental states after death is the result of an intuitive dualism. We have different cognitive mechanisms for dealing with bodies and for dealing with minds. Our reasoning about bodies is governed by intuitive physics (thinking about the motions of bodies in space), whereas our thinking about minds is subserved by intuitive psychology (thinking about beliefs, desires, and other mental states, and how they relate to behavior). Since these two systems are independent, it is possible to attribute mental states to someone whose body has deceased, e.g., when selling grandfather's house, the fact that

\footnotetext{
${ }^{1}$ We focus here on individual cognitive dispositions. For reasons of scope and space, we will not discuss group selectionist theories on supernatural punishment, which propose that belief in supernatural punishment after death is a group-level adaptation that helps people cooperate better (see e.g., Shariff \& Rhemtulla 2012).
} 
grandfather would not have liked this can come vividly to mind even years after his demise. Bloom $(2007,217)$ argues that the cultural transmission of afterlife beliefs builds on this unlearned, intuitive dualism, "while we have to learn the specific sort of afterlife that people in our culture believe in (heaven, reincarnation, spirit world, and so on), the notion that consciousness is separable from the body is not learned at all; it comes for free."

One difficulty with this account of an innate psychological dualism is that it does not seem to be the default position in all religions, as judged from afterlife beliefs. In many religions (e.g., ancient Egypt, Taoism), humans have not one but several souls (Hodge, 2008). Many religions practice the giving of grave gifts, which would be unintelligible if belief in disembodied minds were universal. Other traditions (e.g., Christianity, Islam) hold that people will have a body in the afterlife, e.g., the Fourth Lateran Council (1215) states that God will "judge the living and the dead ... All of them will rise with their own bodies, which they now have," reiterating what Christian theologians have maintained since the second century. The resurrection of the body has been a central belief in Christianity for centuries.

Another difficulty with the view that intuitive dualism is directly causally responsible for afterlife beliefs is that judgments about an agent's psychological continuity beyond death are sensitive to context (Astuti \& Harris 2005). People are more likely to attribute such continuity if they hear about the deceased in a religious context (e.g., a religious funeral) than in a secular context (e.g., a hospital setting). Among westerners, belief in the soul is more prevalent among adults than among children, whereas belief in the afterlife remains more constant throughout life (Anglin, in press). If afterlife beliefs were caused by an intuitive body-soul dualism, one would expect that soul beliefs were as strong as afterlife beliefs in childhood, and that there would be a stronger correlation between these beliefs across cultures.

There are alternative accounts to intuitive dualism. Hodge (2011, in press) argues that our offline social reasoning (i.e., imagining what others might be doing or how they would react, especially while they are not present) requires us to imagine people as embodied and spatially located. When one reasons about someone who is not physically present, one uses theory of mind as well as some representation of salient bodily features (especially those that are important for social interactions, such as the face) to imagine that person. For instance, when Sally thinks of her grandfather in Florida, she imagines him sitting on the porch with grandma, and what he would say or think about her decisions. When he is dead (rather than just far away), she uses the same off-line social reasoning to imagine what he would think of her decision to study architecture rather than medicine. This form of cognition sometimes involves thinking about the other person's bodily states, which may explain why in popular culture, ghosts (deceased people) are still represented as having a body, albeit an insubstantial one. According to Hodge, our capacities for social reasoning make us intuitively conceptualize death as a change in location, rather than the termination of a person. In line with this finding, Gray et al. (2011) found that adult participants think that a person who is in a permanent vegetative state (PVS) has less abilities than a person who is deceased, for instance, a person who is dead still has emotions and feelings, someone in PVS not-after all, the patient in PVS is "stuck" in our world, whereas the dead have agency in the afterlife.

Other authors (e.g., Richert \& Harris 2008, Roazzi et al. 2013) have argued for complex intuitive conceptions of personhood, which involve not just a body and a mind, but also a soul and a spirit. For example, whereas both body and mind change over time, westerners believe the soul does not change to the same extent. Richert 
and Harris (2006) found that western children believe baptism changes a baby's soul but not its mind or body. In Indonesia, the United States, and Brazil, the spirit is associated with passions, whereas the mind is linked to cognitive abilities. The more religious participants are, the more they find the soul important for cognitive, moral, social and bodily abilities (Roazzi et al. 2013). These studies suggest that our intuitive views of personhood are complex-we are not intuitive monists, but no intuitive substance dualists either.

\subsection{Death as unimaginable}

Philosophers, especially in the continental tradition, have argued that it is impossible to think of oneself as not existing, and that it is also very hard to imagine that others have ceased permanently. This might contribute to the formation of afterlife beliefs. As Merleau-Ponty observed, it is not possible to imagine one's own death,

Neither my birth nor my death can appear to me as experiences of my own, since, if I thought of them thus, I should be assuming myself to be pre-existent to, or outliving, myself, in order to be able to experience them, and I should therefore not be genuinely thinking of my birth or my death. I can, then, apprehend myself only as 'already born' and 'still alive' - I can apprehend my birth and my death only as prepersonal horizons: I know that people are born and die, but I cannot know my own birth and death (Merleau-Ponty 2002 [1945], 250).

Heidegger (1996 [1953], 236-246) considered that we can indirectly experience death through the death of others. But this falls short of having phenomenological access to one's own death, since we can still experience the feeling of loss of the other, still see their corpse, etc. What we cannot experience is the end of ourselvesit is literally unimaginable. Even though we are certain we will die, this realization is not part of our lived experience. It is possible to imagine one's own death as an event in the world, but not that one's experiences will come to an end, or differently put, "I can't imagine from the first person perspective that I don't exist" (Nichols, 2007, 219).

Even imagining the death of others, it turns out, is hard and requires cognitive effort. Bering (2002) presented stories where the protagonist died unexpectedly. Adult participants were asked whether the character could still feel hungry, think about his wife, etc. Those who believed people cease permanently at death took longer to answer individual questions about the protagonist's abilities than those who believed in an afterlife. Answering "no" to an epistemic question (e.g., "Can the protagonist still think about his wife?") took twice as long as responding affirmatively. Participants who believed there was no afterlife also made more frequent errors answering the questionnaire. Bering concludes that it is easier to imagine someone's continued existence than someone's death, and that it requires conscious effort to override these intuitive expectations.

The inability to imagine one's own cessation, and the diminished ability to represent the death of others explains a number of cross-cultural features of afterlife beliefs. It explains why afterlife beliefs are cross-culturally widespread, even in cultures where such beliefs are not elaborated and where the hereafter is hardly an attractive place, e.g., Sheol, where the dead live an indistinct existence: "a living dog is better than a dead lion. The living know that they will die, but the dead know 
nothing; they have no more reward, and even the memory of them is lost" (Ecclesiastes 9:4-5 $5^{2}$. In a place like Sheol, a dead person endures a minimalistic existence. The inability to imagine oneself as dead contributes to an intuitive eternalism - our intuitive conceptualization of persons as persisting throughout time. This intuitive eternalism does not force us to believe in an afterlife-it is after all still possible to think about one's own non-existence in the third person (see Nichols, 2007)_but facilitates belief life after death, and may promote the cultural transmission of afterlife beliefs.

\subsection{Mental time travel and positive prospection ${ }^{3}$}

All neurotypical adults have the ability to mentally simulate past, future, and alternative situations. This capacity, termed mental time travel or prospection, allows us to project ourselves into the future in order to consider possible future scenarios. A core brain network underlies both our capacity to remember personal experiences and to imagining future scenarios (Buckner \& Carroll 2007). This brain network is specialized in "scene construction", the production of detailed and spatial representations (Hassabis \& Maguire 2007). In one study, people with hippocampal damage who had amnesia about personal past events and normal control participants were asked to imagine pretty straightforward scenarios (e.g., "Imagine you are lying on a white tropical beach in a beautiful sandy bay"). Controls could easily come up with vivid descriptions, imagining the sun on their skin and the surf on their feet, whereas the amnesic patients had difficulties simulating any kind of perceptual experience (one patient said "The only thing I see is blue") (Hassabis et al. 2007).

Although the brain mechanisms of remembering the past and imagining the future are quite similar, there is one important functional difference: remembering the past is constrained by reality checks (neurotypical people are not serial confabulators like baron von Münchhausen) in a way that future prospection is not. Consistently, across studies, it turns out that people picture their future in optimistic terms: they believe they will be happier, fill in their tax forms more quickly, or make more money, even if there are no compelling reasons to believe so (see van Boven et al. 2008 for review). In line with this biased episodic future thinking, one would expect that more rosy pictures of the afterlife would enjoy greater cultural success. This is a consistent finding. For instance, of the US adult population, $74 \%$ believes in a life after death; the same percentage believes in Heaven, but only $59 \%$ believes in Hell, and even the majority of surveyed adults who believe in Hell are confident they will go to Heaven ${ }^{4}$.

Given the importance of spatial imagery for prospection of future events, one can expect that the most culturally successful afterlife beliefs will be those that provide a detailed, vivid, and concrete visuospatial representation of the locations where this life is led. Representations of paradise tap into an evolved and crossculturally attested preference for park-like landscapes. It is no coincidence that many conceptions of the afterlife resemble lush gardens, e.g., for Muslims and Jehovah's witnesses. These conceptions match the preference for landscapes attested in experimental aesthetics: regardless of their actual surroundings, people prefer environments with some trees, grassland, water, and non-threatening wildlife (Orians

\footnotetext{
${ }^{2}$ All bible citations are from the NRSV.

${ }^{3}$ This section draws from Emmons and De Cruz (manuscript)

${ }^{4} \mathrm{http}$ ///religions.pewforum.org/pdf/report2religious-landscape-study-key-findings.pdf
} 
\& Heerwagen 1992). Yet because afterlife beliefs also have to match existing cultural ideas and practices, they exhibit cross-cultural variability in how they are concretely visualized. Jade palaces are foretold in China, eternal hunting grounds in Native American Plains societies, and lakes full of fat fish in Saami (Scandinavia) culture (Nähri 2008). Afterlife beliefs exemplify culturally variable conceptions of what counts as desirable. To Vikings, Walhalla was a golden hall where warriors could indulge in brawls, rich food, and alcoholic beverages. The Ojibwe (Native American Plains culture) envisage rich hunting grounds where large game hunting is risk-free and always successful,

where the souls find amusement, dancing and game in abundance ... No need to get tired hunting; the best game lets itself be taken without pursuit. The soul of the Indian strikes down the soul of the moose and takes the best pieces of venison, after which the moose gets up unharmed, and starts grazing again (Moon Conard 1901, 76-77).

Mormonism has an elaborate conception of the afterlife, which does not only promise the continuation of the individual after death, but also that of existing social relationships: families are reunited in a beautiful environment, and one can expect to spend eternity with one's loved ones (Davies 2000, chapter 3, see also section 3.2).

\subsection{Death anxiety}

Psychologists (e.g., Greenberg et al. 1986) and anthropologists (e.g., Malinowski, 1948, 29-30) have long speculated that fear of death promotes religious belief, but empirical evidence for this claim has only been gathered in the last few decades. For example, reminding participants of their own mortality makes them more prone to accept creationism and less willing to endorse evolutionary theory (Tracy et al. 2011). Norenzayan and Hansen (2006) found that mortality primes (e.g., a story recounting the tragic death of a boy in a car accident) not only increased belief in God, but also in religious beings that were less culturally salient for the Christian participants, such as the Buddha and shamanic spirits. Jong et al. (2012) used two types of measures to examine the effects of priming mortality on religious and non-religious participants, by first asking them about what they thought would happen if they were dead, and then querying them about their belief in supernatural beings, such as God. Mortality priming increased belief in supernatural beings in religious participants and decreased it in non-religious subjects. However, when belief in supernatural beings was measured implicitly, by asking them to sort, as quickly as possible, words like "angel" and "god" as either imaginary or real, both theists and nontheists sorted more supernatural beings in the real category when primed with mortality.

In spite of this empirical support, many cognitive scientists of religion have criticized the view that fear of death causally contributes to afterlife beliefs (e.g., Boyer, 2002, 236-237). For one thing, afterlives are not uniformly wonderful places; some conceptualize it as a gloomy place where the spirits of the deceased reside, e.g., Yomi in Shintoism, where the dead are in a perpetual state of decomposition. A particularly grim picture of the afterlife comes from Vanuatu (Oceania):

The life in Wies [the hereafter] is not a particularly pleasant one, it seems. The king of this land of the dead is a being called Anrum Mbwilei, who was himself never a living person. He stands in the centre of the village dancing ground in Wies and beats the gongs. He 
beats them so hard that he excretes continually. His excrement is the food of the dead, but ghosts may escape having to eat it by bringing with them from the land of the living the rotten stump of an Erythrina tree (Deacon, 1934, 556).

However, if afterlife beliefs have multiple causal factors, as we propose, one would expect that not all afterlife beliefs help to cope with death anxiety, but that some of them do. Monotheistic religions offer a prospect of Heaven; many reincarnationist religions (e.g., Buddhism, Hinduism) foresee an end to the cycle of death and rebirth in a universal consciousness (e.g., Nirvana). In a study of older western adults, religiosity was one of the independent variables that predicted a lower fear of annihilation (Cicirelli, 2002). Note that afterlife beliefs typically do not eradicate death anxiety and existential questions about life after death-these problems remain present to some extent, as is evident in the fact that sincere believers try to avoid getting killed just like nonbelievers. Martyrs (e.g., in early Christianity) and suicide terrorists, who cheerfully meet their deaths seem to be in the minority. The replacement of religious beliefs with others that offer more pleasant afterlives, as for example, in historic times the replacement of tribal religions in Vanuatu with Christianity (which offers the prospect of Heaven rather than eating excrements), and the replacement of Shinto death rituals with Buddhist funerals in Japan (continued decomposition versus reincarnation or Nirvana) speaks to the fact that people expect a pleasant rather than an unpleasant afterlife (see also previous section).

\section{The problem of personal identity in theological resurrection accounts}

\subsection{Folk and theological concepts of the afterlife}

As we have seen, ordinary cognitive constraints and processes influence the development of afterlife beliefs across cultures. They make human minds receptive to the idea of a postmortem existence. The idea of immortality has also been explored in theology. The question of how persons are able to survive physical death has been the focus of intense theological discussion. Already in Paul's first letter to the Corinthians (15: 35) skeptics question the resurrection of the dead: "How are the dead raised? With what kind of body do they come?" Similarly, in the Qur'an ${ }^{5}$ (17:49), doubters of the Muslim resurrection doctrine muse: "When we are turned to bones and dust, shall we really be raised up in a new act of creation?" What these skeptics allude to is the problem of personal identity: how can I still be "me" in the afterlife, given that my body gets destroyed (rots, burns, etc.) after death?

In accordance with scripture, the accepted Christian doctrine predicts a universal bodily resurrection. However, as scripture does not specify in detail what happens to people after they die, there has been considerable debate on how humans can survive their physical death. For example, while biblical texts foretell a bodily resurrection and a final judgment for everyone, they do not relate in detail how these events will take place, nor do they specify what happens to us in the time between the death of our physical bodies and the Day of Judgment. Does the soul remain in an intermediate state, separate from the body, prior to its unification with a renewed body? Is there a temporal gap in our existence, until we are recreated, as bodies, at the end of times? Such discussions continue among contemporary philosophers who work

\footnotetext{
${ }^{5}$ Translated by M.A.S. Abdel Haleem (2004, Oxford University Press).
} 
on the personal identity problem, for instance, from a physicalist or dualist perspective on human personhood (e.g., van Inwagen 1978 [1998], Zimmerman 2010).

We have argued elsewhere (e.g., De Cruz \& De Smedt 2015, De Cruz 2014), that theologians and philosophers of religion are not immune to the cognitive dispositions that give rise to religious beliefs in laypeople. Theologians build on the intuitive views that laypeople have, typically by making such views more explicit. A key difference between theology and ordinary beliefs is that theologians-like other scholars - aim to be more consistent than laypeople typically are. It is quite common for believers to have religious views that are mildly inconsistent, and for them to be unaware of these inconsistencies. For example, in a qualitative study of afterlife beliefs of a small sample of British Christians (Congregationalists), Armstrong (2011) found that laypeople tend to believe they (and others) go immediately to Heaven after death. There is no mention of an intermediary state (between death and the general resurrection of the dead, such as a soul sleep) or about the Last Judgment. They explicitly say they are disembodied after death, e.g., "the spirit or the soul lives on", "the spirit leaves the body and goes" (Armstrong 2011, 100). The physical resurrection of Jesus was described by one interviewee as "a one-off" (Armstrong 2011, 101), mainly as a way to prove his divinity rather than as a template for the general resurrection. Yet, at the same time, they thought they would hear and see, and have things to do in the afterlife, implying some form of physicality.

As we have seen, humans have the cognitive tendency not only to believe in an afterlife, but also to hold a more general form of eternalism - we find it easy and intuitive to think of ourselves and others not just as having an afterlife, but also a prelife existence. Since young children from cultures that do not have a formal belief in a prelife spontaneously form prelife beliefs, it is unsurprising that such beliefs have emerged in western traditions as well. In Americans who do not formally identify with a religious affiliation but are spiritual seekers, there is a widespread belief in reincarnation: people believe they have lived before, and draw existential meaning from memories they say they have of their previous lives (White et al., in press). Belief in reincarnation has emerged independently multiple times (e.g., Trobriand Islanders, Oceania, the West-African Beng, and Hinduism). Still, prelife beliefs are rarer than afterlife beliefs. There are more motivating factors to believe in an afterlife than to believe in a prelife existence, which probably causes this asymmetry. People miss the dead, but not those who were never born; they fear death, but as the Epicureans already observed, do not fear their prelife lack of existence; they are constrained by reality in their episodic memories, but not in their projections of the future (Emmons \& De Cruz, manuscript).

Intuitive eternalism (both about prelife and afterlife) can potentially conflict with intuitive biology: from about four years of age, young children across cultures understand that death means the cessation of agency and all biological processes, and they can distinguish death from sleep (Barrett \& Behne 2005). At around the same age, young children understand some aspects of reproduction and inheritance, for instance, that cats give birth to kittens and dogs to puppies (Johnson et al. 1997), and they can make inferences about heritable traits, for instance, that a goat, raised by foster kangaroo parents, will climb, rather than hop (Gelman \& Wellman 1991). They understand that birth is the event through which young animals come into existence. Whereas intuitive biology predicts a start and an end to animal and human lives, intuitive eternalism predisposes us to think that human existence extends into the past and the future. One straightforward way to resolve this tension is to endorse that biological processes end, while maintaining that some non-material part (soul or 
spirit) continues to exist. But this form of dualism is at odds with our intuitive tendency to attribute physical features and capacities to the dead. Tensions like these need to be resolved in any theological system of the afterlife. Inevitably, in order to obtain a consistent system, theologians need to introduce counterintuitive elements. In our case study (next subsection) Mormon theologians have introduced a far-reaching monism, and combined this with an intuitive eternalist stance.

Why do theologians try to make internally consistent views? Internal consistency becomes especially important when defending one's views against those of others, but is less important for privately held beliefs that are typically not subject to debate. Mercier and Sperber (2011) propose that checking the coherence of a message is an important way to assess information we receive from others. Thus, theologians have to make explicit in a coherent manner what happens to the body, soul and mind when someone dies, and how a person can survive her physical death. In the next subsection, we look at how Latter-Day Saints (Mormons) view the afterlife, and how they attempt to provide a coherent solution to the question of what happens after death.

\subsection{Mormonism: Physicalist monism and eternalism}

Mormon theology came to a markedly different solution compared to mainstream Christianity (from which it evolved), in that it embraces both a prelife existence and a monism about souls and gods. Joseph Smith, the founder of the Church of Jesus Christ of the Latter-Day Saints, contributed substantially to the distinctive Mormon theology of prelife and afterlife. In 1839, he publicly rejected the idea of creatio ex nihilo and argued that humans exist eternally and necessarily: "The Spirit of Man is not a created being; it existed from Eternity and will exist to eternity. Anything created cannot be eternal, and earth, water \&c - all these had their existence in an elementary state from Eternity" (cited in Ostler, 1982, 61). In the Book of Abraham (1842), he described humans as intelligences that have existed eternally, and that could progress to become like God.

Because of Smith's untimely assassination, many Mormon theological views remained poorly fleshed out. The Mormon theology about prelife and afterlife was mainly developed by Parley Parker Pratt in his essays Materiality (1845) and The immortality and eternal life of the material body (1844) (see Park \& Watkins 2010, for discussion). In these essays, Pratt explicitly argued that "man's body is as eternal as his soul, or his spirit" (cited in Park \& Watkins 2010, 161). In his view, materiality is equivalent to existence: spirits, angels, and God are material and embodied. Immateriality means the same as non-existence. Throughout this radical physicalist monism, there is no ontological divide between the mind and the body, or between God, spirits, and humanity. God has a human (male) body, and humans can progress to become like God. Angels have material bodies too. Spirits are also material, but their material substance is less tangible to our senses. They are humans waiting to be born:

What are Spirits? They are material organizations, intelligences, possessing body and parts in the likeness of the temporal body; but not composed of flesh and bones, but of some substance less tangable to our gross senses in our present life; but tangable to those in the same element as themselves. In short they are men in embrio-Intelligences waiting to come into the natural world and take upon them flesh and bones, that through birth, death, and the resurrection they may also be 
perfected in the material organization. Such was Jesus Christ, and such were we before we came into this world, and such we will be again, in the intervening space between death and the resurrection (Pratt, 1845 [2010], 165).

Spirits are uncreated and co-eternal with God. The difference between intelligent beings (God, angels, humans, spirits) is in the nature and state of their current embodiment. Pratt saw the afterlife as a place where humans would continue in a physical state, eating, drinking, conversing, walking, and playing musical instruments. The idea of an eternal existence of humankind dovetails well with the Mormon concept of eternal progression, i.e., that humans will ultimately become gods: there is no intrinsic ontological distinction between humans and God, but mainly a distinction in stage of development. The majority of Mormons believe that eventually (almost) everyone progresses to the level of God. Gods are (will be) embodied, and thus still resemble us in appearance and actions.

This theology elegantly solves the problem of how we survive our physical deaths: upon birth, physical intelligences acquire flesh and bones, which they shed again after death. After the resurrection, the postmortem life looks very much like our life on Earth, and can thus be easily imagined. Also, Mormonism resonates with our intuitive eternalist tendencies by not only mapping out a detailed afterlife, but also a prelife existence as spirits. The idea that one has a life prior to the present one is, of course, not unique to Mormonism, but it is rare in Christian and post-Christian thought. Origen was one of the few Christian theologians who held that human souls were created prior to the biological conception; this position was declared anathema during the Synod of Constantinople (543).

Not only does the Mormon concept of the afterlife promise a continuation of life as we know it (but for the eternal progression, which is a long-term project), it also preserves social relationships after death, including marital relationships and parent-child bonds. Latter-Day Saints couples can opt to get "sealed", next to being married, which perpetuates their relationship after death. By contrast, in mainstream Christianity, marriages end at death and there are no postmortem marital relationships (Matthew 22:30). Across cultures, people need to come to terms with the tension between their continued social reasoning about dead persons, and their inability to interact with them. As we have seen, humans do not make a distinction between living and dead persons - it is natural to continue to attribute mental states to and have social interactions with the deceased. For instance, in New Ireland (Melanesia), after a mourning period, anthropomorphic sculptures are displayed to channel the social identity of the recently deceased. The sculptures are destroyed or left to rot, which severs the social ties between the living and the dead. This allows survivors to continue life without the deceased, and turns the dead person into an ancestor, someone who is no longer part of the social fabric of the living (Küchler 1992, Gell 1998). The Mormon view of the afterlife is more in line with functional properties of our intuitive social reasoning by its refusal to sever the ties between the living and the dead. According to Davies (2000, chapter 3), Mormonism owes its beginning to some extent to this attractive social view of the afterlife. Indeed, Joseph Smith was deeply struck and saddened by the death of his beloved brother, Alvin, whom he later saw in a vision residing in the celestial kingdom (the highest of the three Mormon heavens).

Latter-Day Saints also assume that humans are begotten (in a biological sense) by God (Heavenly Father) and the elusive Heavenly Mother. While this view accords well with intuitive biological concepts of reproduction, it is in tension with their 
eternalist beliefs. How can people be eternal intelligences, and also be the biological offspring of divine parents? One solution to this problem is that uncreated intelligences are re-organized through the spiritual birth from divine parents. However, this solution is not generally accepted in Mormon theology, and the details of the spiritual birth have yet to be fleshed out (Ostler 1982). Mormonism is a recent offshoot of Christianity which capitalizes on a number of intuitive tendencies, including intuitive eternalism, intuitive biology, and imagining the afterlife as embodied, but it is still struggling to unite these in a coherent theological framework.

\section{Conclusion}

In this essay, we have examined the relationship between intuitive afterlife beliefs and theological concepts of the hereafter. We have shown that several cognitive dispositions render the idea of an afterlife plausible. These include an intuitive conception of personhood as more than just material entity, the tendency to think of persons as eternal, the inability to imagine oneself and others as dead, and an optimistic bias in mental time travel. These cognitive dispositions influence theological views of life after death, as we illustrated with Mormon theological conceptions of the afterlife.

\section{References}

Anglin, S. (in press). On the nature of implicit soul beliefs: When the past weighs more than the present. British Journal of Social Psychology.

Armstrong M. (2011) Extraordinary eschatology: Insights from ordinary theology. In: J. Astley \& L. J. Francis (Eds.), Exploring ordinary theology. Everyday Christian believing and the church (pp. 97-105). Farnham: Ashgate.

Astuti R. \& Harris, P.L. (2008) Understanding mortality and the life of the ancestors in rural Madagascar. Cognitive Science, 32, 713-740.

Barrett, H.C., \& Behne, T. (2005). Children's understanding of death as the cessation of agency: A test using sleep versus death. Cognition, 96, 93-108.

Bering, J.M. (2002). Intuitive conceptions of dead agents' minds: The natural foundations of afterlife beliefs as phenomenological boundary. Journal of Cognition and Culture, 2, 263-308.

Bering, J.M., \& Bjorklund, D. (2004). The natural emergence of reasoning about the afterlife as a developmental regularity. Developmental Psychology, 40, 217-233.

Bloom, P. 2004. Descartes' baby. How child development explains what makes us human. London: Arrow Books.

Bloom, P. (2007). Religion is natural. Developmental science, 10, 147-151.

Buckner, R.L., \& Carroll, D.C. (2007). Self-projection and the brain. Trends in Cognitive Sciences, 11, 49-57. 
Bynum, C.W. (1995). The resurrection of the body in Western Christianity, 200-1336. New York: Columbia University Press.

Cicirelli, V.G. (2002). Fear of death in older adults: Predictions from terror management theory. Journal of Gerontology B: Psychological Sciences and Social Sciences, 57, 358-366.

Davies, D.J. (2000). The Mormon culture of salvation. Aldershot: Ashgate.

Deacon, B. (1934). Malekula: A vanishing people in the New Hebrides (Wedgwood, C.H., Ed.). London: George Routledge \& Sons.

De Cruz, H. (2014). Cognitive science of religion and the study of theological concepts. Topoi. An International Review of Philosophy, 33, 487-497.

Emmons, N.A. \& De Cruz, H. (manuscript). Living forever, but more in the future than in the past: Cognitive dimensions of belief in eternal existence.

Emmons, N.A. \& Kelemen, D. 2014. The development of children's prelife reasoning evidence from two cultures. Child development, 85, 1617-1633.

Gell, A. (1998). Art and agency. An anthropological theory. Oxford: Clarendon Press.

Gelman, S.A., \& Wellman, H.M. (1991). Insides and essences: Early understandings of the non-obvious. Cognition, 38, 213-244.

Giménez-Dasí, M., S. Guerrero, and P.L. Harris. 2005. Intimations of immortality and omniscience in early childhood. European Journal of Developmental Psychology, 2, 285-297.

Gray, K., Knickman, T.A., \& Wegner, D.M. (2011). More dead than dead: Perceptions of persons in the persistent vegetative state. Cognition, 121, 275-280.

Greenberg, J., Pyszczynski, T. \& Solomon, S. (1986). The causes and consequences of a need for self-esteem: A terror management theory. In R.F. Baumeister (Ed.), Public self and private self (pp. 189-212). New York: Springer.

Hassabis, D., Kumaran, D., Vann, S., \& Maguire, E. (2007). Patients with hippocampal amnesia cannot imagine new experiences. Proceedings of the National Academy of Sciences USA, 104, 1726-1731.

Hassabis, D., \& Maguire, E.A. (2007). Deconstructing episodic memory with construction. Trends in cognitive sciences, 11, 299-306.

Heidegger, M. (1996 [1953]). Being and time (trans. J. Stambaugh). Albany: State University of New York Press. 
Hodge, K.M. (2008). Descartes' mistake: How afterlife beliefs challenge the assumption that humans are intuitive Cartesian substance dualists. Journal of Cognition and Culture, 8, 387-415.

Hodge, K.M. (2011). On imagining the afterlife. Journal of Cognition and Culture, 11, $367-389$.

Hodge, K.M. (in press). The death we fear is not our own. In: H. De Cruz \& R. Nichols (Eds.), Advances in religion, cognitive science, and experimental philosophy. New York \& London: Continuum.

Jong, J., Halberstadt, J., \& Bluemke, M. (2012). Foxhole atheism, revisited: The effects of mortality salience on explicit and implicit religious belief. Journal of Experimental Social Psychology, 48, 983-989.

Küchler, S. (1992). Making skins: Malangan and the idiom of kinship in Northern New Ireland. In J. Coote \& A. Shelton (Eds.), Anthropology, art and aesthetics (pp. 94-112). Oxford: Clarendon Press.

Malinowski, B. (1948). Magic, science and religion and other essays. Glencoe: Free Press.

Mercier, H. \& Sperber, D. (2011). Why do humans reason? Arguments for an argumentative theory. Behavioral and Brain Sciences, 34, 57-74.

Merleau-Ponty, M. (2002 [1945]). Phenomenology of perception (trans. C. Smith). London \& New York: Routledge.

Moon Conard, E.L. (1901). Les idées des indiens algonquins relatives a la vie d'outre-tombe. Paris: Ernest Leroux.

Murphy, N. (2006). Bodies and souls or spirited bodies? Cambridge: Cambridge University Press.

Nähri, J. (2008). Beautiful reflections: The cognitive and evolutionary foundations of paradise representations. Method and Theory in the Study of Religion, 20, 339365 .

Nichols, S. (2007). Imagination and immortality: thinking of me. Synthese, 159, 215233.

Norenzayan, A., \& Hansen, I.G. (2006). Belief in supernatural agents in the face of death. Personality and Social Psychology Bulletin, 32, 174-187.

Orians, G.H., \& Heerwagen, J.H. (1992). Evolved responses to landscapes. In J. Barkow, L. Cosmides, \& J. Tooby (Eds.), The adapted mind: Evolutionary psychology and the generation of culture (pp. 555-579). New York: Oxford University Press. 
Ostler, B.T. (1982). The idea of pre-existence in the development of Mormon thought. Dialogue, 15, 59-78.

Park, B.E. \& Watkins, J.T. (2010). The riches of Mormon materialism: Parley P. Pratt's "Materiality" and early Mormon theology. Mormon Historical Studies, 11, 159-172.

Pratt, P.P. (1845 [2010]). Materiality. Reprinted in Park, B.E. \& Watkins, J.T. (2010). The riches of Mormon materialism: Parley P. Pratt's "Materiality" and early Mormon theology. Mormon Historical Studies, 11, 164-167.

Richert, R.A., \& Harris, P.L. (2006). The ghost in my body: Children's developing concept of the soul. Journal of Cognition and Culture, 6, 409-427.

Richert, R.A., \& Harris, P.L. (2008). Dualism revisited: Body vs. mind vs. soul. Journal of Cognition and Culture, 8, 99-115.

Roazzi, M., Nyhof, M., \& Johnson, C. (2013). Mind, soul and spirit: Conceptions of immaterial identity in different cultures. International Journal for the Psychology of Religion, 23, 75-86.

Shariff, A. F., \& Rhemtulla, M. (2012). Divergent effects of beliefs in Heaven and Hell on national crime rates. PloS One, 7, e39048.

Sumney, J. L. (2009). Post-mortem existence and resurrection of the body in Paul. Horizons in Biblical Theology, 31, 12-26.

Tracy, J.L., Hart, J., \& Martens, J.P. (2011). Death and science: The existential underpinnings of belief in Intelligent Design and discomfort with evolution. PLoS ONE, 6, e17349.

Van Boven, L., Kane, J., \& McGraw, A.P. (2008). Temporally asymmetric constraints on mental simulation: Retrospection is more constrained than prospection. In $\mathrm{K}$. Markman, W. Klein, \& S. Shur (Eds.), The handbook of imagination and mental simulation (pp. 131-149). New York: Psychology Press.

Van Dyke, C. (2007). Human identity, immanent causal relations, and the principle of non-repeatability: Thomas Aquinas on the bodily resurrection. Religious Studies, 43, 373-394.

van Inwagen, P. (1978). The possibility of resurrection. International Journal for Philosophy of Religion, 9, 114-121.

White, C., Kelly, R., \& Nichols, S. (in press). Remembering past lives. In H. De Cruz $\&$ R. Nichols (Eds.), Advances in religion, cognitive science, and experimental philosophy. New York \& London: Continuum.

Zimmerman, D.W. (2010). The compatibility of materialism and survival. Faith and Philosophy, 16, 194-212. 
